\title{
PEPTIDASES SECRETADAS POR FUNGOS TERMOFILICOS: uma revisão sistemática
}

Tatiane Beltramini SOUTO ${ }^{1}$

Nathalia Gonsales da ROSA ${ }^{2}$

\begin{abstract}
${ }^{1}$ Bióloga, Doutora, Faculdade de Ciências Farmacêuticas, Departamento de Ciências Farmacêuticas, Universidade de São Paulo - FCFRP/USP, Ribeirão Preto - S.P. e-mail: tatianebelt@ yahoo.com.br

${ }^{2}$ Bacharel em Biotecnologia, Pós-graduanda, Doutorado, Faculdade de Ciências Farmacêuticas, Departamento de Ciências Farmacêuticas, Universidade de São Paulo - FCFRP/USP, Ribeirão Preto - S.P. e-mail: nathaliagrosa@gmail.com
\end{abstract}

Endereço de correspondência e-mail: tatianebelt@yahoo.com.br

Recebido em: 23/11/2014 - Aprovado em: 01/06/2015 - Disponibilizado em: 15/07/2015

RESUMO: Peptidases são enzimas que atuam sobre as ligações peptídicas de proteínas e peptídeos, liberando peptídeos e/ ou aminoácidos. São comercializadas em todo o mundo e abrange cerca de $60 \%$ do comércio de enzimas, devido sua vasta aplicação em diferentes setores industriais. As características desejáveis para uma peptidase aplicável a indústria são: termoestabilidade, estabilidade a variação de $\mathrm{pH}$, solventes orgânicos entre outros. A busca por enzimas termoestáveis contribui para o aumento de estudos envolvendo fungos termofilos, pois estes micro-organismos possuem a termofilia como característica fisiológica, são de fácil cultivo, se comparado a bactérias, e secretam enzimas. O processo de obtenção não requer equipamentos refinados para a obtenção enzimática tornando a manufatura do produto mais barata. Esta revisão realizou o levantamento de estudos com fungos termófilos e peptidases nos últimos dez anos dez anos, a fim de relatar a importância desses fungos e as peptidases por eles produzidas bem como seu potencial de aplicação.

Palavras chaves: Peptidases. Aplicação industrial. Fungos termofílicos. Termoestabilidade. Classificação de peptidases.

\section{PEPTIDASES SECRETED BY THERMOPHILIC FUNGI: a systematic review}

ABSTRACT: Peptidases are enzymes which act on peptide bonds of proteins and peptides, releasing peptides and/or amino acids. These enzymes are commercialized worldwide and cover about $60 \%$ of the enzyme market, because of their wide application in different industrial sectors. Desirable characteristics of peptidases for industrial application are: thermostability, stability at a $\mathrm{pH}$ range, organic solvents among others. The search for thermostable enzymes contributes to the increase of studies involving thermophilic fungi, since these microorganisms have thermophilic ability (have the ability to grow at high temperatures) as the main physiological characteristic, they are easy to grow, compared to bacteria, and secrete enzymes. Processes to obtain enzymes do not need refined equipments, what makes product manufacture cheaper. This review was based on a survey made on studies made in the past ten years with thermophilic fungi and their peptidases as well as their potential application.

Keywords: Peptidases. Industry application. Thermophilic fungi. Thermostability. Peptidases classifications. 


\section{Introdução}

\subsection{Peptidases: ação $\quad$ e classificação}

Peptidases são enzimas presentes em todos os organismos vivos e provavelmente surgiram no início da evolução biológica. Estas enzimas atuam através da hidrólise de ligações peptídicas que levam à formação de peptídeos e/ou aminoácidos livres, dependendo do modo de ação (RAO et al., 1998).

Segundo a União Internacional de Bioquímica e Biologia Molecular (I.U.B) as peptidases são classificadas como hidrolases $\mathrm{n}^{\circ} 3$, pertencentes ao subgrupo 4 (E.C.3.4), porém a classificação destas enzimas é mais complexa que isso e pode ser dividida de acordo com outros critérios, tais como: a ação catalítica; a natureza do sítio catalítico; $\mathrm{pH}$ ótimo de ação; fonte de obtenção e a conformidade com suas estruturas. A classificação pela ação catalítica está relacionada com o modo de ação sobre à ligação peptídica podendo ser classificada como: endopeptidases que clivam ligações peptídicas atuam nas regiões internas das cadeias polipeptídicas, entre as regiões amino e carboxiterminal e exopeptidases que atuam nas extremidades carboxi e amino-terminal das cadeias polipeptídicas (RAWLINGS e BARRET, 1993).
O critério da natureza do sítio catalítico da peptidase está relacionado à existência de resíduos de aminoácidos no sítio ativo enzimático que são essenciais para desempenho catalítico das peptidases. Assim, as peptidases são agrupadas em: aspártico peptidases, cisteíno peptidases, metalo peptidases (dependência de íons metálicos), serino peptidases, (RAWLING et al., 2004) treonina peptidases e glutâmico peptidases (PUENT e LOPEZ, 2004). Em relação ao pH ótimo de ação catalítica as peptidases podem ser classificadas em ácidas, neutras e alcalinas. Finalmente, as peptidases também podem ser classificadas em função da sua fonte de obtenção como de origem animal, vegetal e microbiana (PALMA et al., 2002).

\subsection{Potencial econômico das peptidases}

O mercado de enzimas técnicas vende aproximadamente US\$ 1 bilhão, e cerca de $30 \%$ deste mercado é constituído de enzimas destinadas a produtos de limpeza (BON et al., 2008).

Dentre todas as enzimas aplicadas industrialmente, as peptidases constituem um dos grupos mais importantes por representarem aproximadamente $60 \%$ das enzimas mundialmente comercializadas e são empregadas em detergentes, carne, couro, depilação, produção de inseticidas, tratamento 
de resíduos e indústria farmacêutica (MERHEB et al., 2007).

$\mathrm{Na}$ maioria dos trabalhos científicos, as bactérias são relatadas como os principais micro-organismos produtores de peptidase, porém o potencial de fungos filamentosos também tem sido explorado (GUIMARÃES et al., 2006).

\subsection{Peptidases e aplicação industrial}

Peptidases exibem ampla aplicação biotecnológica e são utilizadas em uma grande extensão de processos industriais (ANWAR e SALEEMUDDIN, 1998) e por isso, destacam-se perante o mercado mundial de enzimas como as mais importantes. São aplicadas na indústria de detergentes (VENUGOPAL e SARAMMA, 2006), amaciamento da carne (GENCKAL e TARI, 2006), clarificação da cerveja, indústria do leite, maturação de queijos, síntese de peptídeos, conversão de resíduos naturais em biomassa usual (chifre, penas e pêlos) (ANWAR e SALEEMUDDIN, 1998), produção de gelatinas com diferentes graus de endurecimento, fabricação de inseticidas (WANH e HSU, 2005) e ainda na substituição da catálise química em processos industriais (MEHTA et al., 2006).

A aplicação biotecnológica das peptidases é promissora tendo em vista tendências para o desenvolvimento de tecnologias protetoras do meio ambiente juntamente com o grande potencial econômico (RAO et al., 1998).

A elevada capacidade dos fungos em secretar proteínas para o meio tem sido explorada na produção de enzimas com aplicação biotecnológica e industrial (ODA et al., 2006). Esse comportamento também é observado na natureza, uma vez que fungos saprófitos produzem uma grande diversidade de enzimas extracelulares que permitem a adaptação do metabolismo fúngico aos substratos disponíveis (KIM et al., 2007).

\subsection{Peptidases fúngicas}

A utilização de fungos pela humanidade é remota.

A produção de proteínas por fungos filamentosos é mais atrativa do que por bactérias, uma vez que os fungos são capazes de produzir grandes quantidades de proteínas extracelulares e algumas espécies já possuem a certificação GRAS (Generally Recognized as Safe) para indústria de alimentos. Além disso, os fungos possuem rápido crescimento quando comparado com outras células eucarióticas e são capazes de secretar proteínas funcionais com enovelamento correto e com as modificações póstraducionais necessárias (KOSALKOVA et al., 2012). 
A introdução de fungos de forma geral como fonte de obtenção de enzimas também trouxe a busca por enzimas termoestáveis, que conferem vantagens no processo industrial (ZANOELO et al., 2004) e consequentemente aumentou do interesse pelos fungos classificados como termófilos.

Os fungos termófilos representam uma pequena parcela da comunidade fúngica que exibe resistência ao calor como característica fisiológica distinta e, embora a utilização destes micro-organismos seja interessante poucos trabalhos são realizados com os mesmos, principalmente envolvendo peptidases.

\subsection{Fungos termofílicos enzimas}

Mucor pusillus foi o nome dado ao primeiro fungo termofílico, isolado do pão e descrito por Lindt há pouco mais de um século (MAHESHWARI, 2000). Posteriormente, Tsiklinskaya descobriu outro fungo termofílico o Thermomyces lanuginosus crescendo em batatas.

O habitat natural de fungos termofílicos e as condições bióticas que favorecem seu crescimento ficaram desconhecidos até que Hugo Miehe investigou as causas do auto aquecimento e combustão espontânea de palheiro (MAHESHWARI et al., 2000).
Fungos termófilos são conhecidos por produzirem enzimas termoestáveis, possuem uma temperatura ótima de crescimento entre $40^{\circ} \mathrm{C}$ e $50^{\circ} \mathrm{C}$ (GOMES et al., 2007). O uso destas enzimas pode apresentar muitas vantagens, especialmente na indústria de alimentos, devido às altas temperaturas de processamentos que podem ser aplicadas, as quais estão relacionadas com o aumento na taxa de reação, melhorando a solubilidade dos reagentes e diminuição na ocorrência de contaminação por micro-organismos mesofílicos (MACCHIONE et al., 2008).

A maioria dos micro-organismos eucariotos são incapazes de sobreviver a temperaturas próximas a $40-45^{\circ} \mathrm{C}$ por um tempo prolongado, e esta capacidade está presente em aproximadamente 30 espécies de um total de 100 mil fungos, portanto a habilidade de violar altas temperaturas é um fenômeno que merece ser mais estudado (MAHESHWARI et al., 2000).

Neste contexto, este trabalho tem como objetivo destacar a importância de peptidases secretadas por fungos termofilicos na aplicação industrial e verificar a necessidade do aumento de estudos sobre este assunto a partir de revisão literária sistemática. 


\section{Metodologia}

Foi realizada a busca de artigos científicos com os descritores: "thermophilic fungus and proteases". As buscas eletrônicas foram feitas em julho e agosto de 2014, limitadas ao idioma Inglês e as datas das publicações analisada foram de 2004 a 2014 nas seguintes bases de dados: ScienceDirect e Pubmed. Após as buscas, os artigos foram selecionados de acordo com o assunto proposto.

\section{Discussão}

As peptidases integram um dos grupos mais importantes de enzimas aplicadas na indústria (HADDAR et al., 2009). Neste cenário, as peptidases microbianas têm destaque (GUPTA et al., 2002) dada as vantagens e custos envolvidos no seu manuseio e cultivo em relação as peptidases obtidas de vegetais e animais.

As características dos fungos termofílicos e extremofílicos (GOMES e STEINER, 2004) levam a produção de enzimas termoestáveis, que são desejáveis para sua aplicação à indústria. Logo, peptidases produzidas por estes micro-organismos, na maioria das vezes são termoestáveis e aceitas para aplicação industrial.

Um levantamento sobre a utilização de peptidases produzidas por fungos termófilos permitirá uma análise sobre as deficiências científicas no que tange o conhecimento sobre estes micro-organismos, enzimas e seus respectivos potenciais. Neste contexto, existe um aumento no interesse por peptidases secretadas por fungos termófilos, entretanto estes estudos ainda são incipientes e representam um nicho para ser explorado (Figura 1).

$\mathrm{Na}$ abordagem utilizada neste estudo, entre os anos de 2004 e 2014 foram identificados 10 estudos com fungos termófilos e produção de peptidases (Figura 1). Os anos entre $2007 \mathrm{e}$ 2012 apresentaram um maior número de publicações, principalmente para a aplicação biotecnológica destas enzimas nas indústrias de hidrolisados do leite e detergentes.

A seguir serão relatadas publicações disponíveis na literatura que tratam de peptidases secretadas por fungos termofílicos bem como possíveis aplicações industriais.

Merheb e colaboradores (2007) realizaram uma caracterização parcial da peptidase secretada pelo fungo termófilo Thermoascus aurantiacus. 
Figura 1 - Publicações envolvendo peptidases e fungos termófilos de 2004 - 2014.

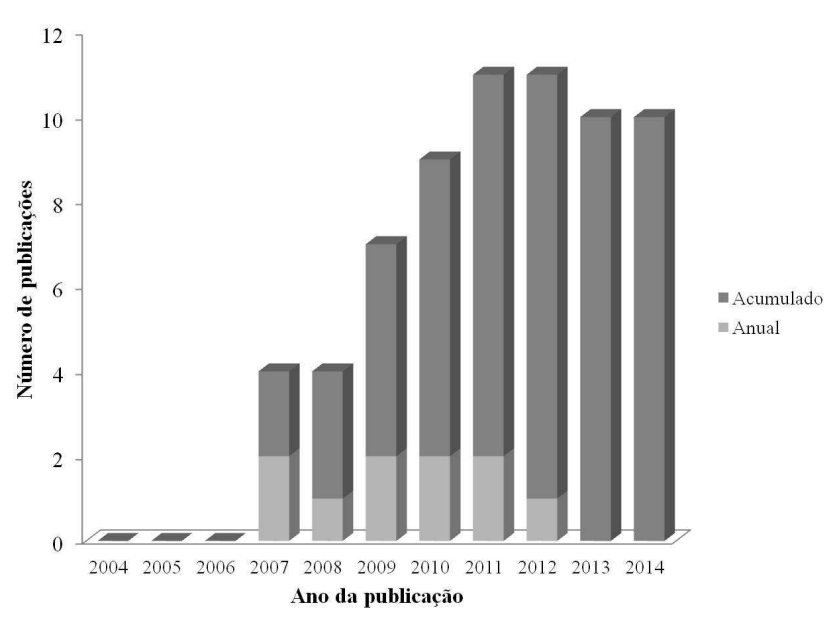

Fonte: Próprios autores

Os parâmetros bioquímicos revelaram uma enzima termoestável em temperaturas acima de $60^{\circ} \mathrm{C}$ e estável em ampla faixa de $\mathrm{pH}(3,0$ a 9,5). Estudos aplicados mostraram que esta peptidase causa hidrólise excessiva da caseína do leite e sugeriu-se a aplicação desta peptidase em processos que necessitem de atividade proteolítica em altas temperaturas.

No mesmo ano, um grupo de pesquisa apresentou a purificação e a caracterização de duas peptidases secretadas pelo fungo termofílico Chaetomium thermophilum. Os resultados obtidos revelaram a existência de duas peptidases com massa molecular de aproximadamente 33 e $63 \mathrm{kDa}$ e pH ótimo 10 e 5, respectivamente. A peptidase de menor massa molecular $(\mathrm{kDa})$ mostrou conservar $67 \%$ de sua atividade após $1 \mathrm{~h}$ de incubação a $70^{\circ} \mathrm{C}$ que representa uma termoestabilidade maior comparada a peptidase de massa molecular $63 \mathrm{kDa}$. Os autores ainda sugerem um possível uso industrial destas enzimas devido as suas características e propõem mais estudos aplicados para a especificação destas aplicações (LI et al., 2007).

$$
\text { Macchione e colaboradores }
$$
compararam a produção de peptidases em fermentação submersa e sólida secretadas por nove diferentes fungos termófilos com o objetivo de verificar as melhores condições de cultivo para a secreção de peptidases. $\mathrm{Na}$ fermentação em estado sólido os fungos que se destacaram foram Thermomyces lanuginosus, T. lanuginosus TO.03, Aspergillus sp. 13.34, Aspergillus sp. 13.35 e Rhizomucor sp. 13.37, enquanto que na fermentação submersa a secreção de peptidases foi maior pelos fungos Thermoascus aurantiacus, T. lanuginosus TO.03 e T. lanuginosus 13.37 .

Merheb et al. (2009) realizaram estudos bioquímicos e de caracterização com a peptidase secretada pelo fungo Thremoascus aurantiacus. Os autores sugeriram que a peptidase era uma metalo peptidase embasados na inibição de sua atividade por EDTA e ativação pelo íon $\mathrm{Fe}^{2+}$. A possível metalo peptidase apresentou $\mathrm{pH}$ ótimo 5,5 e após $1 \mathrm{~h}$ a $65^{\circ} \mathrm{C}$ conservou $70 \%$ de sua atividade residual. Estudos com substrato fluorescente Abz-KLXSSKQED-Dnp 
revelaram a preferência da peptidase em questão pelo resíduo de arginina em $\mathrm{P}_{1}$.

Em 2009, Li e Li apresentaram os resultados de estudos moleculares e bioquímicos que envolveram a clonagem e expressão em Pichia pastori de uma serino peptidase de Chaetomium thermophilum. A peptidase recombinante purificada foi caracterizada e apresentou atividade catalítica ótima em pH 8,0 e temperatura de $60^{\circ} \mathrm{C}$. Sua estabilidade ao $\mathrm{pH}$ apresentou atividades residuais superiores a $80 \%$ na faixa de $\mathrm{pH}$ de 7 a 12 . A peptidase manteve cerca de $80 \%$ e $50 \%$ de atividade residual após 60 minutos de exposição a $60^{\circ} \mathrm{C}$ e $70^{\circ} \mathrm{C}$, respectivamente.

No início do ano de 2010 Merheb-Dini e colaboradores publicaram um trabalho envolvendo a produção e caracterização de peptidases isoladas do termófilo Thermomucor indicae-seudatica N31 que realizavam a coagulação do leite. Os autores sugeriram a aplicação destas peptidases na indústria de queijos, pois os resultados demonstraram a alta coagulação do leite e baixa atividade proteolítica após vinte e quatro horas de fermentação. As propriedades bioquímicas da peptidase bruta exibiram uma baixa ação proteolítica sobre a caseína do leite bovino e a ação coagulante foi ótima em $\mathrm{pH}$ 5,7 e a $70^{\circ} \mathrm{C}$. O perfil de peptídeos obtidos encorajou os pesquisadores a investigarem o potencial desta enzima como uma possível renina microbial.

Em 2010, Zanphorlin e colaboradores (2010) produziram, caracterizaram parcialmente e imobilizaram em "beads" de alginato de cálcio peptidases secretadas por um nova espécie do gênero do termófilo Myceliophthora sp. A fermentação em estado sólido em meio de cultura composto por farelo de trigo e caseína permitiu que o fungo produzisse 4,5 vezes mais peptidases quando comparada com a quantidade de enzima obtida na fermentação líquida. A peptidase presente no extrato bruto apresentou $\mathrm{pH}$ ótimo 7 e 9 de acordo com o tipo de fermentação líquida ou em estado sólido, respectivamente. A peptidase alcalina obtida na fermentação sólida foi imobilizada em alginato de cálcio e os resultados mostraram que a termoestabilidade da peptidase imobilizada foi superior a da peptidase livre.

No ano seguinte, Li e colaboradores (2011) clonaram e expressaram uma peptidase secretada pelo fungo termófilo Thermoascus aurantiacus var. levisporus em P. pastoris e caracterizaram a peptidase recombinante. As condições ótimas foram temperatura de $50^{\circ} \mathrm{C}$ e $\mathrm{pH} 8,0$. Em estudos de termoestabilidade, a peptidase apresentou atividade residual de aproximadamente $100 \%, 80 \%$ e $60 \%$ após 60 minutos de exposição a 50, 60 e $70^{\circ} \mathrm{C}$, respectivamente. A peptidase foi inibida por 
PMSF, mas não por DTT e EDTA e exibiu uma alta atividade frente a diferentes substratos proteicos como caseína, gelatina, albumina bovina, hemoglobina bovina e leite.

No ano de 2011, o grupo de Zanphorlin e colaboradores (2011) continuou a estudar a peptidase secretada pelo fungo termófilo Myceliophthora sp. e realizaram a purificação e caracterização desta enzima. A inibição por PMSF indicou a classificação da peptidase isolada como serino-peptidase e o $\mathrm{pH}$ e temperatura ótimos foram 9 e $40-45^{\circ} \mathrm{C}$, respectivamente. Estudos de fluorescência com substrato peptídico sintético com supressão intramolecular de fluorescência revelaram a especificidade de algumas peptidases.

O potencial para uma renina microbiana deu início a uma investigação mais aprofundada sobre a peptidase produzida por $T$. indicaeseudaticae N31. Em 2012, Merheb-Dini e colaboradores (2012) aplicaram a peptidase estudada anteriormente para a coagulação do queijo prato e compararam os índices de coagulação com um coagulante comercial. Os resultados obtidos não mostraram diferenças entre a coagulação proporcionada pela peptidase secretada por $T$. indicae-seudaticae N31 e pelo coagulante comercial durante os sessenta dias de maturação do queijo.
Embora este trabalho saliente a importância da produção e dos estudos de peptidases produzidas por fungos termófilos, nos anos de 2013 e 2014 nenhum trabalho foi encontrado para peptidases secretadas por fungos termófilos nas condições de busca anteriormente apresentadas.

\section{Considerações finais.}

A termoestabilidade é uma característica importante para peptidases com potencial de aplicação industrial. Os fungos termofílicos são micro-organismos que secretam enzimas com esta desejável característica, além disso, não exigem métodos refinados para a obtenção enzimática como as bactérias, nem cuidados extremos de cultivo como os extremófilos. Nos últimos dez anos alguns trabalhos foram encontrados principalmente entre os anos de 2007 á 2012, porém poucas pesquisas ainda são realizadas com peptidases e fungos termófilos. Devido à importância das peptidases na indústria de forma geral acreditamos que exista necessidade de mais pesquisas nesta área.

\section{Referências}

ANWAR, A.; SALEEMUDDIN, M. Alkaline proteases: A review. Bioresource

Technology, v. 64, n. 3, p. 175-183, Jun 1998. 
BON, E. P. S.; FERRARA, M. A.; CORVO, M. L. Enzimas em biotecnologia: Produção, aplicação e mercado, 1. Ed. Rio de Janeiro: Interciência, 506 p, 2008.

GENCKAL, H.; TARI, C. Alkaline protease production from alkalophilic Bacillus sp isolated from natural habitats. Enzyme and Microbial Technology, v. 39, n. 4, p. 703710, Aug 22006.

GOMES, E. et al. Enzimas termoestáveis: Fontes, Produção e Aplicação Industrial, Química Nova. V. 30, n. 1, p. 136-145, Aug 2007.

GOMES, J.; STEINER, W. The biocatalytic potential of extremophile and extremozymes. Food Technology Biotechnology. v. 42, p. 223-235, Nov 2004.

GUIMARÃES, L. H. S. et al. Screening of filamentous fungi for production of enzymes of biotecnological interest. Brazilian Journal of Microbiology, v. 32, n. 4, p. 474-480, Dec 2006.

GUPTA, R.; BEG, Q. K.; LORENZ, P. Bacterial alkaline proteases: molecular approaches and industrial applications. Applied Microbiology and Biotechnology, v. 59, n. 1, p. 15-32, Jun 2002.
HADDAR, A. et al. Two detergent stable alkaline serine-proteases from Bacillus mojavensis A21: Purification, characterization and potential application as a laundry detergent additive. Bioresource Technology, v. 100, n. 13, p. 3366-3373, Jul 2009.

LI, A.-N. et al. Purification and characterization of two thermostable proteases from the thermophilic fungus Chaetomium thermophilum. Journal of Microbiology and Biotechnology, v. 17, n. 4, p. 624-631, Apr 2007.

LI, A.-N. et al. Cloning, Expression, and Characterization of Serine Protease from Thermophilic Fungus Thermoascus aurantiacus var. levisporus. Journal of Microbiology, v. 49, n. 1, p. 121-129, Feb 2011.

LI, A. N.; LI, D. C. Cloning, expression and characterization of the serine protease gene from Chaetomium thermophilum. Journal of Applied Microbiology, v. 106, n. 2, p. 369380, Feb 2009.

KIM, Y.; NANDAKUMAR, M.P.; MARTEN, M.R. Proteomics of filamentous fungi. TRENDS in Biotechnology, v.25, p.395-400, Aug 2007. 
KOSALKOVÁ, K.. et al Casein

phosphopeptides drastically increase the

secretion of extracellular proteins in

Aspergillus awamori. Proteomics studies

reveal changes in the secretory pathway.

Microbial Cell Factories, v.11, p.15, Jan 2012.

MACCHIONE, M. M. et al. Protease

production by different thermophilic fungi.

Applied Biochemistry and Biotechnology,

v. 146, n. 1-3, p. 223-230, Mar 2008.

MERHEB, C. W. et al. Partial

characterization of protease from a

thermophilic fungus, Thermoascus

aurantiacus, and its hydrolytic activity on bovine casein. Food Chemistry, v. 104, n. 1, p. 127-131, Jan 2007.

MERHEB-DINI, C. et al. Biochemical and

Functional Characterization of a

Metalloprotease from the Thermophilic

Fungus Thermoascus aurantiacus. Journal of Agricultural and Food Chemistry, v. 57, n. 19, p. 9210-9217, Oct 142009.

MERHEB-DINI, C. et al. Production and characterization of a milk-clotting protease in the crude enzymatic extract from the newly isolated Thermomucor indicae-seudaticae N31 (Milk-clotting protease from the newly isolated Thermomucor indicae-seudaticae
N31). Food Chemistry, v. 120, n. 1, p. 87-93, May 12010.

MERHEB-DINI, C. et al. Use of a new milkclotting protease from Thermomисor indicaeseudaticae $\mathrm{N} 31$ as coagulant and changes during ripening of Prato cheese. Food Chemistry, v. 130, n. 4, p. 859-865, Feb 15 2012.

MEHTA, V. J.; THUMAR, J. T.; SINGH, S. P. Production of alkaline protease from an alkaliphilic actinomycete. Bioresource Technology, v. 97, n. 14, p. 1650-1654, Sep 2006.

ODA, K.. et al. Proteomic analysis of extracellular proteins from Aspergillus oryzae grown under submerged and solid-state culture conditions. Appl Environ Microbiol, v.72, p.3448-3457, May 2006.

PALMA, J. M. et al. Plant peptidases protein degradation, and oxidative stress: role of peroxisomes. Plant Physiology

Biochemistry, v. 40, p. 521-530, Aug 2002.

PUENTE, X. S.; LOPEZ-OTIN, C. A

Genomic Analysis of Rat Proteases and Protease Inhibitors. Genome Biology, v. 14, p.609-622, Jan 2004. 
RAO, M. B. et al. Molecular and

biotechnological aspects of microbial

proteases. Microbiology and Molecular

Biology Reviews, v. 62, n. 3, p. 597-635, Sep 1998.

RAWLING, N. D.; BARRETT, A. J.

Evolutionary families of peptidases.

Biochemical Journal. v. 290, p. 205-218, 1993.

RAWLING, N. D.; TOLLE, D. P.; BARREY,

A. J. Merops: the peptidases database.

Nucleic Acids Research, London, v.27, n1, p. 325-331, Jan 2004.

VENUGOPAL, M.; SARAMMA, A. V.

Characterization of alkaline protease from

Vibrio fluvialis strain VM10 isolated from a

mangrove sediment sample and its application as a laundry detergent additive. Process

Biochemistry, v. 41, n. 6, p. 1239-1243, Jun 2006.
WANG, H.-T.; HSU, J.-T. Optimal protease production condition for Prevotella ruminicola 23 and characterization of its extracellular crude protease: Anaerobe. v 11, p. 155-162, Jun 2005.

ZANOELO, F. F. et al. B- glucosidase activity from thermophilic fungus Scytalidium thermophilum is stimulated by glucose and xylose. Fems Letters Microbiology. v. 240, p. 137-143, Nov 2004.

ZANPHORLIN, L. M. et al. Production, Partial Characterization, and Immobilization in Alginate Beads of an Allkaline Protease from a New Thermophilic Fungus Myceliophthora sp. The Journal of Microbiology. v. 48, n.3, p.331-338, Jan 2010.

ZANPHORLIN, L. M. et al. Purification and characterization of a new alkaline serine protease from the thermophilic fungus Myceliophthora sp. Process Biochemistry, v.46, p.2137-2143, Aug 2011. 